\title{
Self-reported Disability in Patients with Inflammatory Bowel Disease Largely Determined by Disease Activity and Illness Perceptions
}

\author{
Mike van der Have, MD, ${ }^{1}$ Herma H. Fidder, PhD, ${ }^{1}$ Max Leenders, PhD, ${ }^{1}$ Ad A. Kaptein, PhD, ${ }^{2}$ \\ Mirthe E. van der Valk, MD, ${ }^{1}$ Ad A. van Bodegraven, PhD, ${ }^{3,4}$ Gerard Dijkstra, PhD, ${ }^{5,6}$ Dirk J. de Jong, PhD, ${ }^{7}$ \\ Marieke Pierik, PhD, ${ }^{8}$ Cyriel Y. Ponsioen, PhD, ${ }^{9}$ Andrea E. van der Meulen-de Jong, PhD, ${ }^{10}$ \\ C. Janneke van der Woude, PhD, ${ }^{11}$ Paul C. van de Meeberg, PhD, ${ }^{12}$ Mariëlle J. L. Romberg-Camps, PhD, ${ }^{4}$ \\ Cees H. M. Clemens, PhD, ${ }^{13}$ Jeroen M. Jansen, MD, ${ }^{14}$ Nofel Mahmmod, MD, ${ }^{15}$ Clemens J. M. Bolwerk, MD, ${ }^{16}$ \\ J. Reinoud Vermeijden, MD, ${ }^{17}$ Peter D. Siersema, PhD, ${ }^{\text {C }}$ and Bas Oldenburg, PhD, ${ }^{1}$ on behalf of the COIN \\ study group and the Dutch Initiative on Crohn and Colitis
}

Background: The inflammatory bowel disease (IBD) disability index has recently been introduced to measure patients' physical, psychological, familial, and social limitations associated with IBD. We assessed factors related to self-reported disability and the relationship between disability and direct health care costs.

Methods: A large cohort of patients with Crohn's disease (CD) and ulcerative colitis (UC) was prospectively followed for 2 years by 3 monthly webbased questionnaires. At 2 years, patients completed the IBD disability index, with lower score indicating more disability. Linear regression analysis was used to examine the impact of demographics, clinical characteristics, and illness perceptions on self-reported disability. Trends in direct health care costs across the disability severity groups minimal, mild, moderate, and severe, were tested.

Results: A total of 554 patients with CD and 424 patients with UC completed the IBD disability index (response rate, 45\%). Both clinical characteristics and illness perceptions significantly contributed to self-reported disability $(45 \%-47 \%, P=0.000$ and $8 \%-12 \%, P=0.000$, respectively). Patients with CD scored lower on the self-reported IBD disability index than patients with UC $(0.255$ versus $3.890, P<0.000)$, indicating more disability in patients with CD. Factors independently associated with higher self-reported disability rates were increased disease activity, illness identity (higher number of symptoms attributed to IBD), and stronger emotional response. Disease duration and disease phenotype were not associated with self-reported disability. Direct health care costs increased with the worsening of self-reported disability $(P=0.000)$.

Conclusions: More disability was reported by patients with CD than by UC. Self-reported disability in IBD was mainly determined by clinical disease activity and illness perceptions but not by disease duration or disease phenotype.

(Inflamm Bowel Dis 2015;21:369-377)

Key Words: IBD disability index, illness perceptions, determinants, health care costs

Supplemental digital content is available for this article. Direct URL citations appear in the printed text and are provided in the HTML and PDF versions of this article on the journal's Web site (www.ibdjournal.org).

Received for publication August 26, 2014; Accepted October 8, 2014.

From the ${ }^{1}$ Department of Gastroenterology and Hepatology, University Medical Center Utrecht, the Netherlands; ${ }^{2}$ Medical Psychology Section, Leiden University Medical Center,

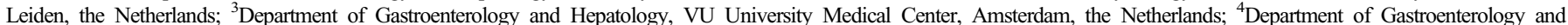

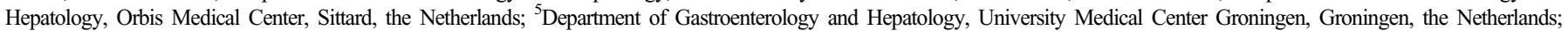
${ }^{6}$ University of Groningen, Groningen, the Netherlands; ${ }^{7}$ Department of Gastroenterology and Hepatology, Radboud University Nijmegen Medical Center, Nijmegen, the Netherlands;

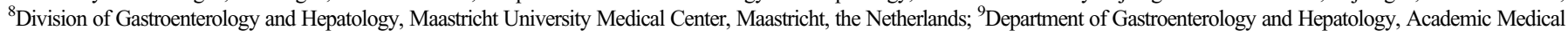

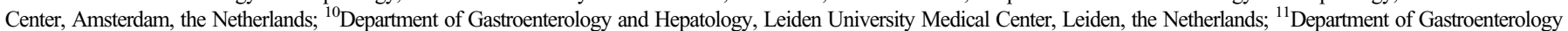

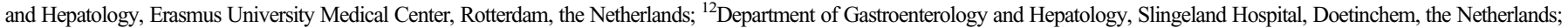

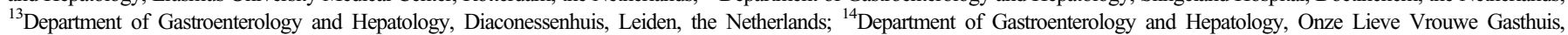

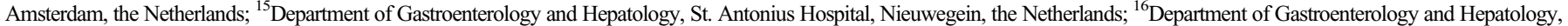
Reinier de Graaf Groep, Delft, the Netherlands; and ${ }^{17}$ Department of Gastroenterology and Hepatology, Meander Medical Center, Amersfoort, the Netherlands.

Supported by an unrestricted grant from AbbVie.

All authors have completed and submitted the ICMJE Form for Disclosure of Potential Conflicts of Interest. A. A. van Bodegraven has acted as a consultant for AbbVie,

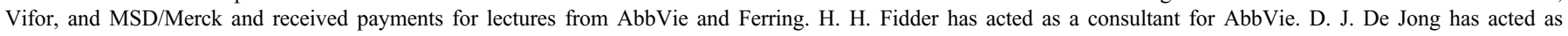
a consultant for Synthon Netherlands and received payments for lectures from AbbVie, Ferring, and MSD. A. A. Kaptein has received payments for lectures from Ferring and

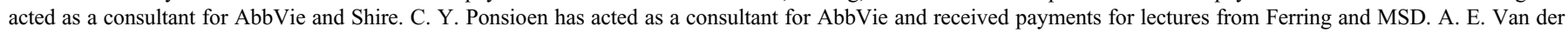

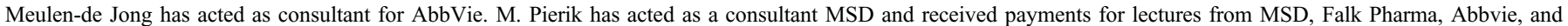

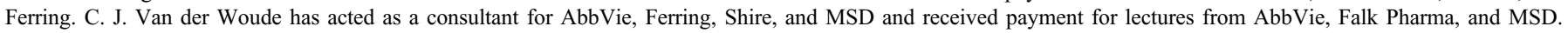
B. Oldenburg has received payments for lectures from Ferring and acted as a consultant for AbbVie and MSD.

Reprints: Bas Oldenburg, PhD, Department of Gastroenterology and Hepatology, University Medical Center Utrecht, Heidelberglaan 100 , 3584 CX Utrecht, the Netherlands (e-mail: b.oldenburg@umcutrecht.nl).

Copyright (C) 2015 Crohn's \& Colitis Foundation of America, Inc.

DOI 10.1097/MIB.0000000000000278

Published online 7 January 2015. 
$\mathrm{T}^{\mathrm{h}}$ he natural history of Crohn's disease (CD) and ulcerative colitis (UC) is characterized by periods of relapse and remission, potentially leading to intestinal damage, and surgery over time. ${ }^{1,2}$ This may induce a wide spectrum of physical, psychological, familial, and social problems. ${ }^{3,4}$ Both widely used symptomassessment tools and quality of life (QOL) questionnaires cannot provide a reliable assessment of these problems., ${ }^{5,6}$ Therefore, Peyrin-Biroulet et al recently developed the inflammatory bowel disease (IBD) disability index to objectively and comprehensively cover the range of functional limitations in IBD. ${ }^{7}$ This tool is thought to be useful for clinical practice, disease modification trials, and health reporting in IBD. ${ }^{7,8}$

The IBD disability index is based on the WHO's International Classification of Functioning, Health, and Disability. ${ }^{9}$ This classification describes the impact of illness on a patient as a dynamic interaction between illness, personal, and environmental factors. Functioning is subdivided into the activity and the participation component, including regulating defecation, interpersonal activities, and work. The health-related component consists of body structures, such as blood in stool and arthritis/ arthralgia, and body functions, such as energy, sleep, and body image. Personal and environmental factors are recognized as mediating factors for the association between these 2 components.

Important mediating factors are the patient's illness perceptions. According to the Common Sense Model, ${ }^{10}$ these illness perceptions or patient beliefs may attenuate the impact of clinical characteristics on clinical outcomes, including disability, QOL, and distress. ${ }^{11-13}$

In contrast to other chronic illnesses, such as rheumatoid arthritis, ${ }^{14}$ data on disability in IBD are scarce. Most studies in IBD on this topic have a retrospective design, ${ }^{15,16}$ are small, or are focused on work disability. ${ }^{17,18}$ In a prospective validation study of 166 participants, the interview-based IBD disability index has been reported to be reliable, reproducible, sensitive for detecting disability, with a good correlation with the Crohn's Disease Activity Index, Mayo index, and Inflammatory Bowel Disease Questionnaire. ${ }^{19}$

This study aimed to assess: (1) the severity of self-reported disability and functional limitations, (2) determinants of selfreported disability, (3) the impact of self-reported disability on direct health care costs (DHC) and QOL in a nationwide cohort of patients with IBD.

\section{METHODS}

\section{Patient Population and Study Design}

The Costs Of Inflammatory bowel disease In the Netherlands ("COIN") cohort was established in 2010. This is an ongoing study of adult patients with $\mathrm{CD}$ and UC from 7 general and 8 university hospitals in the Netherlands who were identified between 2007 and 2010, using Diagnosis-Treatment-Combination codes. Patients completed 3 monthly web-based questionnaires including questions about demographics, clinical characteristics, and resource utilization. The cohort is described in more detail in a previous report. ${ }^{20}$ The study was centrally approved by the Ethics Committee of the University Medical Center Utrecht, Utrecht.

The primary outcome of interest, self-reported disability (hereafter referred to as "disability"), was measured with the IBD disability index 24 months after study entry. Most information on demographic and clinical and behavioral determinants of disability was collected concurrently. Data concerning smoking, education, comorbid conditions, and disease localization were assessed at baseline. Of the 3015 patients who were included in the COIN study, 505 (17\%) were lost to follow-up. Patients who were lost to follow-up were more likely to be female $(P=0.021)$, smoker $(P=0.000)$, and had a lower education level $(P=0.000)$ than those patients with IBD who were not lost to follow-up.

\section{Determinants}

Determinants of disability were based on previous studies on factors independently associated with work disability or a disabling disease course, encompassing stricturing or penetrating disease, requiring abdominal surgery or immunomodulators (see Table, Supplemental Digital Content 1, http://links.lww.com/IBD/A674).

Demographic determinants included gender, age, smoking status (current smoker, exsmoker, nonsmoker), and education level (low versus high). Low education included no education, primary education, secondary education, and technical or professional school, whereas high education included higher vocational education and university.

Clinical determinants included comorbid conditions (selfreported depression, joint complaints, chronic back pain), age at diagnosis, disease duration, localization at enrollment for CD (ileal, colonic, ileocolonic), penetrating disease course for CD (defined as perianal fistula or other fistula), previous IBD-related surgery, stoma, pouch, and medical treatment at enrollment (mesalazine, corticosteroids, immunomodulators, anti-TNF agents). Previous IBD-related surgery compromised intestinal resections and perianal operations.

Behavioral determinants included illness perceptions, which were assessed with the Brief Illness Perception Questionnaire. ${ }^{21}$ This 9-item questionnaire explores the cognitive and emotional representations of illness across 8 dimensions: Consequences, Timeline, Personal Control, Treatment Control, Identity, Concerns, Understanding, and Emotional Response. Items are assessed on an 11-point Likert scale; e.g., "How much does your illness affect your life?": 0 ["not at all"]-10 ["severely affects my life"].

\section{IBD Disability Index}

The IBD disability index consists of 28 questions, exploring limitations across 5 International Classification of Functioning, Health, and Disability domains: Overall Health, Body Functions (sleep/energy, affect, body image, pain, diarrhea, body mass index, weight loss), Activities and Participation (regulating defecation, looking after one's health, interpersonal activities, and work/education), Body Structures (blood in stool, arthralgia/arthritis), and Environmental Factors (exacerbating effect of medication, food, family, and health care professional). ${ }^{7}$ 
A validated scoring system was used to measure the presence and severity of disability in the previous week with lower or negative scores indicating greater disability (see Data, Supplemental Digital Content 2, http://links.lww.com/IBD/A675). ${ }^{19}$ The total score on the IBD disability index ranges between -80 (maximum degree of disability) and 22 (no disability). The severity of disability was categorized into minimal $(>-10)$, mild $(-10$ to -19$)$, moderate $(-20$ to -35$)$, and severe $(\leq-35) .{ }^{19}$ The majority of questions are scored by patients on a 5-point Likert scale ("no," "mild," "moderate," "severe or extreme limitations"), whereas other questions included a dichotomous answer ("yes" or "no").

\section{DHC and QOL}

DHC included costs related to outpatient hospital visits, diagnostic procedures medication use, stoma appliance use, IBDrelated hospitalizations, and IBD-related surgeries. DHC were calculated by multiplying self-reported units of resource utilization by their unit costs. ${ }^{22}$

QOL was measured by the validated Dutch translation of the Inflammatory Bowel Disease Questionnaire-32, encompassing 32 items, with a graded response range of "worst" (1) to "best" (7) and a possible total score of 32 to 224 . $^{6,23}$

\section{Statistical Analysis}

Data analyses were performed using SPSS 20.0 and SAS 9.2. Descriptive statistics were used to characterize patients with $\mathrm{CD}$ and UC. Means and medians were reported with a SD and interquartile range, respectively. Comparisons between $\mathrm{CD}$ and $\mathrm{UC}$ were analyzed with Student's $t$ test for continuous variables and $\chi^{2}$ or Fisher's exact test for dichotomous variables. The IBD disability index was translated into the self-reported IBD disability index by 4 authors (B.O., H.H.F., A.A.K., M.H.), following the forwardbackward-forward technique. Two randomly selected groups of 10 outpatients with IBD filled out the self-reported IBD disability index, followed 1 week later by an interview-based IBD disability index (group 1) or vice versa (group 2). The reproducibility of the IBD disability index was assessed with the reliability coefficient by Bland and Altman. ${ }^{24}$ Correlation analyses were performed to assess associations between demographic, clinical and behavioral determinants, and the IBD disability score (see Table, Supplemental Digital Content 3, http://links.lww.com/IBD/A678). Variables that reached at least a borderline statistical significance $(P<0.10)$ in the correlation analyses were included in the hierarchical linear regression analysis, which is based on the Common Sense Model. ${ }^{10}$ Tests for trends in DHC across the categories minimal, mild, moderate, and severe disability were conducted by using the median value in each category as a continuous variable in the linear regression models.

\section{RESULTS}

\section{Patient Population}

In total, 1108 patients with IBD (response rate: 45\%) were enrolled, including 554 patients with CD (50\%), 424 patients with
UC (38\%), and 130 patients with "IBD-unknown/unclassified" $(12 \%)$ (Fig. 1). Patients with "IBD-unknown/unclassified" were excluded from further analyses.

Table, Supplemental Digital Content 4, http://links.lww.com/ IBD/A676 shows data on baseline demographic and clinical characteristics in both the responders (CD: $n=554$ and UC: $n=424$ ) and nonresponders (CD: $n=726$ and UC: $n=479)$. There were no relevant statistical significant differences between both groups.

Patients with $\mathrm{CD}$ were more likely to be female $(58 \%$ versus $45 \%, P=0.000)$, smoker (20\% versus $7 \%, P=0.000)$, had a lower age at diagnosis (30.7 versus $36.0 \mathrm{yr}, P=0.000)$, a higher probability of having a stoma (14\% versus $5 \%)$, and a lower probability of having a pouch $(2 \%$ versus $9 \%, P=$ 0.000 ) as compared with patients with UC. Patients with CD were more frequently treated with immunomodulators $(31 \%$ versus $21 \%, P=0.000)$ and/or anti-TNF agents $(21 \%$ versus $4 \%, P=$ $0.000)$ as compared with patients with UC.

\section{Self-reported IBD Disability Index: Internal Consistency, Reproducibility}

The internal consistency/reproducibility (Cronbach's $\alpha$ ) for the 5-point Likert questions was 0.872 . The total scores showed a good reproducibility between the patient-reported and interview-based IBD disability index, with a $95 \%$ probability that the total score on the second IBD disability index fell within the Bland and Altman coefficient of repeatability. Reproducibility was comparable for group 1 and group 2 .

\section{Severity of Disability and Functional Limitations}

Patients with CD scored significantly lower on the selfreported IBD disability index as compared with patients with UC

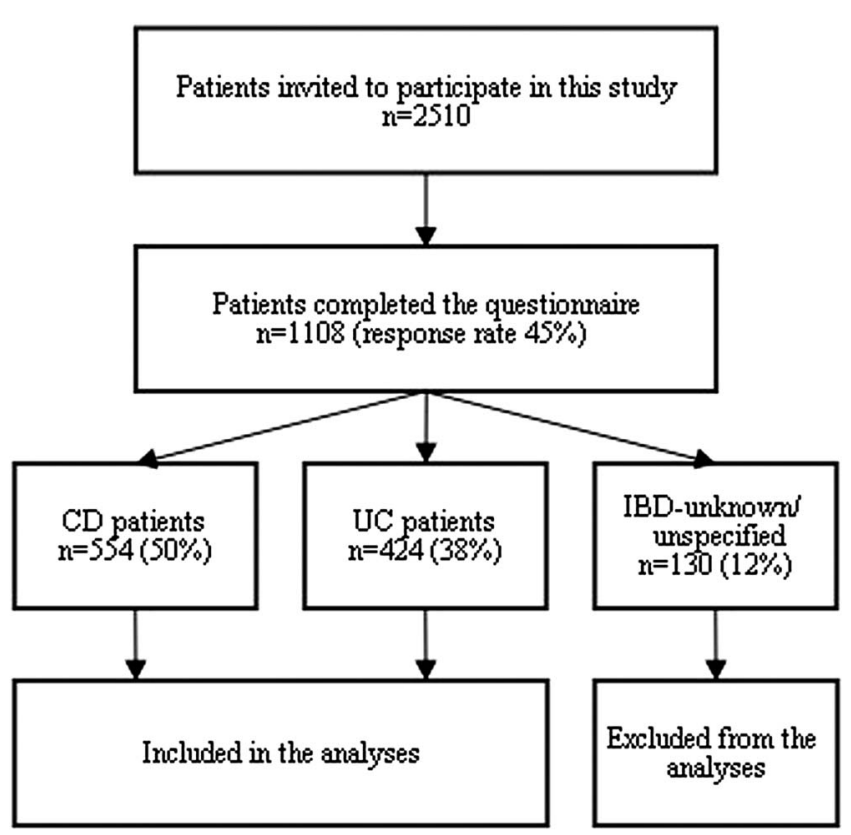

FIGURE 1. Study flow-chart. 


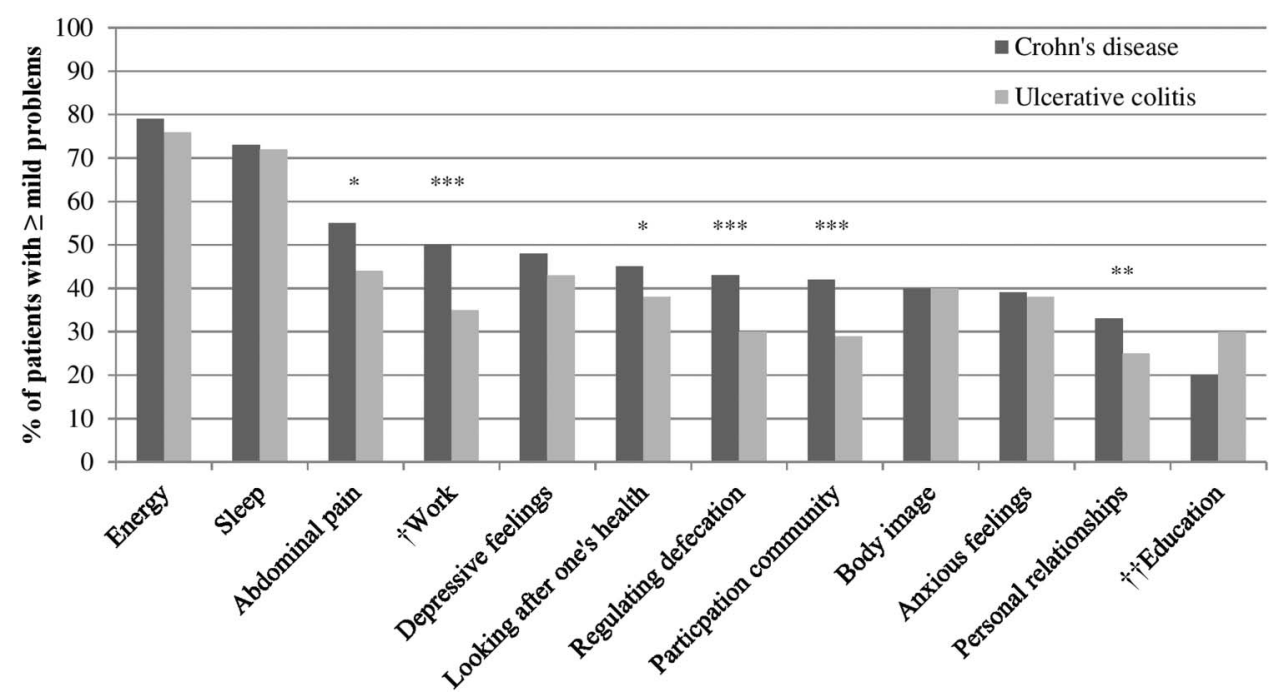

FIGURE 2. Functional limitations in patients with $C D(n=554)$ and UC $(n=424)$. +Patients with CD (333) and UC (274) were used or partially disabled. †+Patients with CD (20) and UC (10) were student. ${ }^{*} P<0.05 ;{ }^{* *} P<0.01$; ${ }^{* * *} P<0.001$.

(0.255 versus $3.890, P<0.000)$, indicating a greater disability in $\mathrm{CD}$. Problems that were most frequently reported by both $\mathrm{CD}$ and UC patients were related to sleep and abdominal pain (Fig. 2). Patients with CD reported significantly more problems related to abdominal pain $(55 \%$ versus $44 \%, P=0.022)$, regulating defecation (43\% versus $30 \%, P=0.027$ ), looking after one's health $(45 \%$ versus $38 \%, P=0.000)$, participation in the community ( $42 \%$ versus $29 \%, P=0.000$ ), personal relationships (33\% versus $25 \%, P=0.005)$, and work $(50 \%$ versus $35 \%$, $P=0.000)$ as compared with patients with UC.

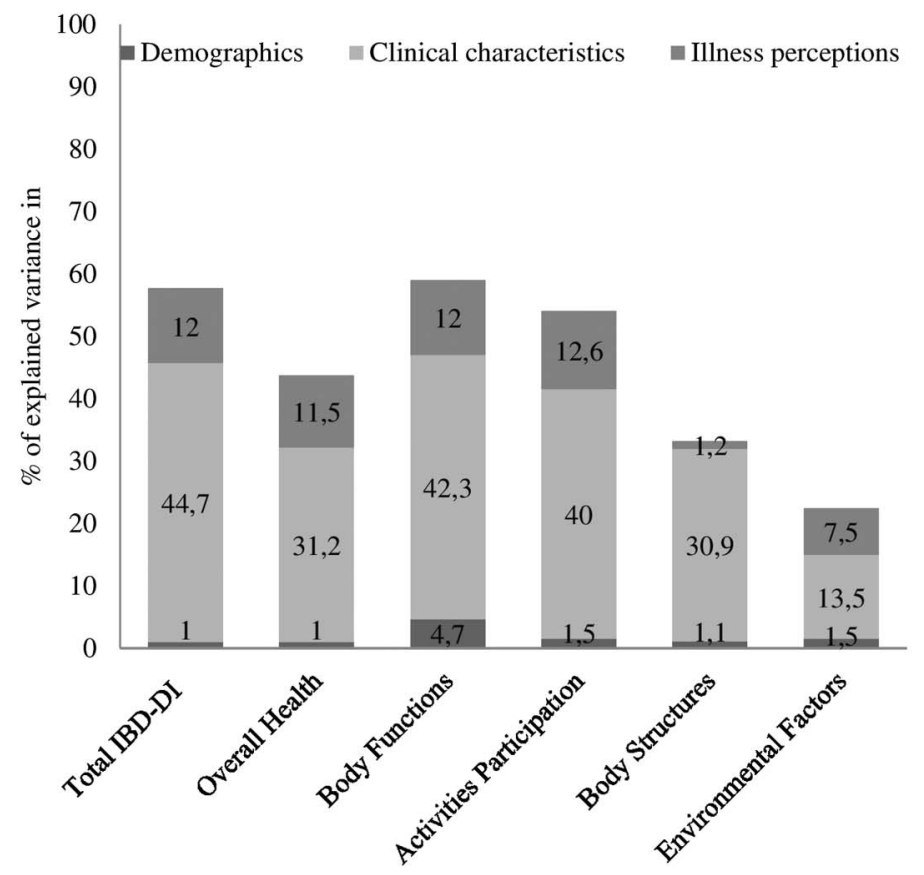

IBD-DI = self-reported IBD disability index. Demographics contributed to a significant proportion of the variance in total IBD-DI $(p<0.05)$ and domain sub-scores $(p<0.000)$, except for Overall Health $(p=0.061)$. Clinical characteristics and illness perceptions contributed to a significant proportion of the variance in IBD-DI and domain sub-scores $(\mathrm{p}<0.000)$.

FIGURE 3. Percentages of variance in self-reported disability total and domain subscores by demographic (step 1), clinical (step 2), and behavioral variables (step 3$)$ in patients with $C D(n=554)$. 


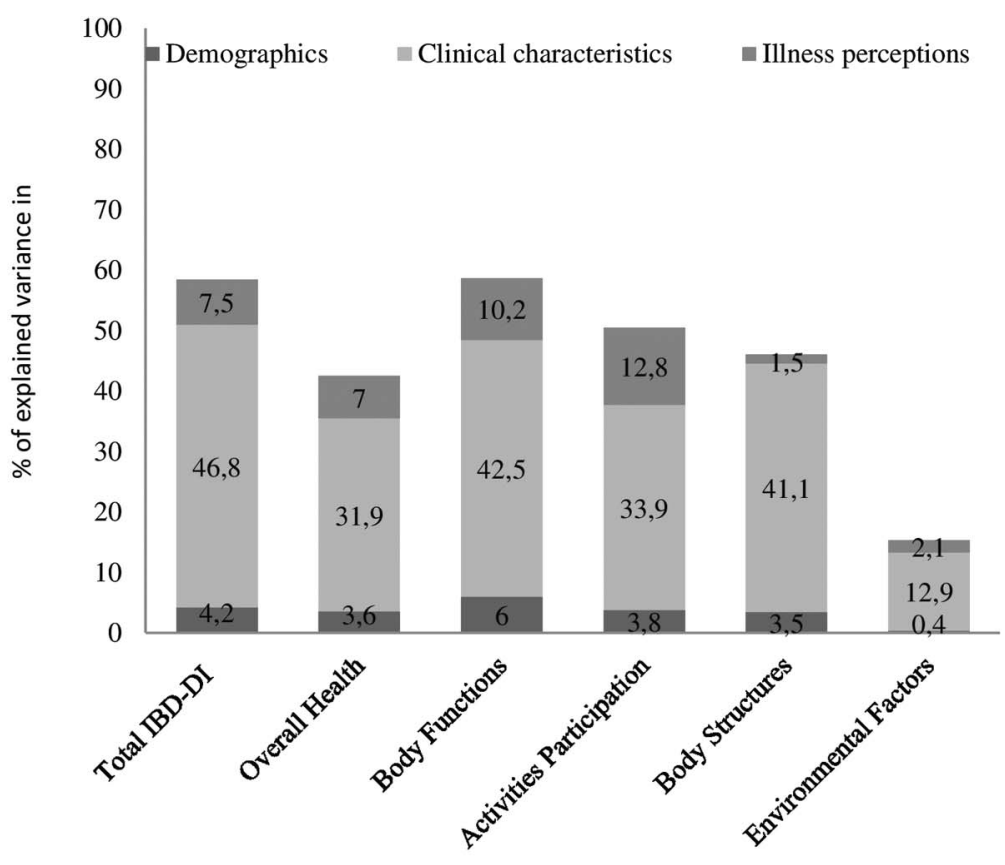

IBD-DI = self-reported IBD disability index. Demographics contributed to a significant proportion of the variance in total IBD-DI $(\mathrm{p}<0.000)$ and domain sub-scores $(\mathrm{p}<0.000)$, except for Environmental Factors $(\mathrm{p}=0.472)$. Clinical characteristics and illness perceptions contributed to a significant proportion of the variance in IBD-DI and domain sub-scores $(\mathrm{p}<0.000)$.

FIGURE 4. Percentages of variance in self-reported disability and domain subscores by demographic (step 1), clinical (step 2), and behavioral variables (step 3$)$ in patients with UC $(n=424)$.

\section{Determinants of Disability}

Multiple hierarchical regression analyses were performed to assess the contributory role of demographic (step 1), clinical (step 2), and behavioral (e.g., illness perceptions) determinants (step 3) in determining the IBD disability index total and its domain subscores. In patients with $\mathrm{CD}$, demographic, clinical, and behavioral determinants contributed towards a significant proportion of explained variance in total IBD disability score, namely $1.0 \%(P<0.05), 44.7 \%(P<0.001)$, and $12.0 \%(P<$ 0.001 ), respectively (Fig. 3). Factors that were independently associated with greater disability included clinical disease activity $(\beta=-5.696 ; 95 \% \mathrm{CI},-8.763$ to -2.629$)$, previous CD-related surgery $(\beta=2.279 ; 95 \% \mathrm{CI}, 0.647-3.912)$, self-reported depression $(\beta=-5.696 ; 95 \% \mathrm{CI},-8.763$ to $-2.629)$, and the illness perceptions Personal Control $(\beta=$ 0.354 ; 95\% CI, $0.047-0.661)$, identity $(\beta-0.940 ; 95 \% \mathrm{CI}$, -1.464 to -0.416$)$, and Emotional response $(\beta=-0.522$; $95 \%$ CI, -0.949 to -0.094 ) (Table 2). In patients with UC, demographic, clinical, and behavioral determinants contributed towards a significant proportion of explained variance in total IBD disability score, namely $4.2 \%(P<0.001), 46.8 \%(P<$ $0.001)$, and $7.5 \%(P<0.001)$, respectively (Fig. 4). Factors that were independently associated with greater disability included clinical disease activity $(\beta=-2.891 ; 95 \% \mathrm{CI},-3.385$ to
$-2.396)$ and the illness perceptions Identity $(\beta=-0.643$; $95 \% \mathrm{CI},-1.218$ to -0.067$)$, and Emotional response $(\beta=$ $-0.497 ; 95 \% \mathrm{CI},-0.926$ to -0.068 ) (Table 2).

\section{Relationship Between Mean DHC, QOL, and Self-reported IBD Disability Severity}

Of the total 1108 patients with IBD, minimal, mild, moderate, and severe disability were present in 901 (81.3\%), 129 (11.6\%), $70(6.3 \%)$ and $8(0.7 \%)$ patients, respectively (see Fig., Supplemental Digital Content 5, http://links.lww.com/IBD/A677). A statistically significant increasing linear trend $(P=0.000)$ in DHC as disability increased was demonstrated. In addition, a statistically significant decreasing linear trend $(P=0.000)$ in mean QOL scores as disability increased was demonstrated.

\section{DISCUSSION}

In this Dutch nationwide cohort, we observed that disability was mainly determined by clinical disease activity and illness perceptions. Typical characteristics of a complicated disease course, including disease duration, penetrating disease, ileal involvement, or surgery, were not associated with disability. Additionally, we found that greater disability was associated with higher DHC and a lower QOL. 
TABLE 1. Demographic and Clinical Characteristics of the Study Population

\begin{tabular}{|c|c|c|c|}
\hline & $\mathrm{CD}(\mathrm{n}=554)$ & $\mathrm{UC}(\mathrm{n}=424)$ & $P$ \\
\hline \multicolumn{4}{|l|}{ Demographic characteristics } \\
\hline Male gender $(\%)$ & $232(42)$ & $234(55)$ & 0.000 \\
\hline Age $( \pm S D), y r$ & $55.0(13.4)$ & $56.4(12.6)$ & 0.100 \\
\hline Current smoker (\%) & $108(20)$ & $28(7)$ & 0.000 \\
\hline Low education $(\%)$ & $345(62)$ & $232(55)$ & 0.114 \\
\hline \multicolumn{4}{|l|}{ Clinical characteristics } \\
\hline \multicolumn{4}{|l|}{ Comorbid conditions $(\%)$} \\
\hline Depression & $46(8)$ & $31(7)$ & 0.789 \\
\hline Joint complaints & $160(28)$ & $91(21)$ & 0.030 \\
\hline Chronic back pain & $59(11)$ & $37(9)$ & 0.316 \\
\hline Age at diagnosis $( \pm S D), y r$ & $30.7(12.7)$ & $36.0(13.5)$ & 0.000 \\
\hline $\begin{array}{l}\text { Disease duration, median } \\
\text { (IQR) }\end{array}$ & $19.5(10.5-31.5)$ & $16.5(9.5-24.2)$ & 0.000 \\
\hline \multicolumn{4}{|l|}{ Disease localization (\%) } \\
\hline Large bowel & $165(30)$ & & \\
\hline Small bowel & $119(22)$ & & \\
\hline $\begin{array}{l}\text { Both large and small } \\
\text { bowel }\end{array}$ & $255(46)$ & & \\
\hline Unknown & $15(3)$ & & \\
\hline $\begin{array}{l}\text { Penetrating disease course } \\
(\%)\end{array}$ & $283(51)$ & & \\
\hline $\begin{array}{l}\text { Previous IBD-related } \\
\text { surgery }\end{array}$ & $313(57)$ & $74(18)$ & 0.000 \\
\hline Stoma $(\%)$ & $76(14)$ & $21(5)$ & 0.000 \\
\hline Pouch $(\%)$ & $13(2)$ & $40(9)$ & 0.000 \\
\hline \multicolumn{4}{|l|}{ Medication use (\%) } \\
\hline Mesalazine & $131(24)$ & $281(66)$ & 0.000 \\
\hline Steroids & $47(9)$ & $27(6)$ & 0.225 \\
\hline Immunosuppressant & $170(31)$ & $87(21)$ & 0.000 \\
\hline Anti-TNF $\alpha$ agents & $115(21)$ & $15(4)$ & 0.000 \\
\hline
\end{tabular}

To our knowledge, this is the largest study to date, assessing functional disability in patients with IBD with the recently introduced IBD disability index. This index has previously demonstrated to be reliable, reproducible, and sensitive for detecting disability. ${ }^{19}$ It has also shown to have a good correlation with existing symptom-assessment tools and with the Inflammatory Bowel Disease Questionnaire. However, as the IBD disability index needs to be completed by a physician, implementation into clinical practice is challenging. Therefore, we studied the agreement between the patient-reported and interviewbased IBD disability index and found a good reproducibility (repeatability coefficient $\geq 0.95$ ) between these 2 indices.

It seems plausible that a complicated disease course in IBD - characterized by strictures, fistulas, and surgeries - leads to intestinal dysfunction, surgery, and a progressive deterioration of the functional status. ${ }^{25}$ Yet, in line with previous studies, ${ }^{15,26}$ we found that disability was mainly determined by clinical disease activity and illness perceptions but not by characteristics of a complicated disease course.

In a small pilot study of 38 patients with IBD, it has been found that perceived disability (as measured with the Perceived Disability Scale) was moderately to strongly associated with bowel health, systemic health, more abdominal pain, less engagement in daily activities, higher perceived stress, and a higher number of gastroenterologist visits. ${ }^{15}$ Perceived disability was not significantly associated with disease duration, hospitalizations, and history of surgeries. In a recent study among 244 patients with long-term IBD from the population-based Manitoba Cohort study, it has been found that disability (as measured with World Health Organization Disability Assessment Schedule) was associated with long-term clinical disease activity and a history of major depression but not with disease duration, previous IBD surgeries, or disease phenotype. ${ }^{26}$

In addition, we found that disability was strongly associated with several illness perceptions. Illness perceptions accounted for $1 \%$ to $13 \%$ of the explained variance in disability, in addition to demographic $(1 \%-5 \%)$ and clinical characteristics $(13 \%-47 \%)$. This finding is in line with the results of a previous study that showed that illness perceptions accounted for $23 \%$ of the explained variance in disability (as measured with the Functional Limitations Profile), in addition to demographic variables (23\%) and coping (6\%). ${ }^{16}$ Our findings corroborate the Common Sense Model, in which it is stated that individual's personal beliefs about IBD play a major role in the adjustment to the illness. ${ }^{10,27}$

In both $\mathrm{CD}$ and UC patients, illness identity was strongly and independently associated with disability. This indicates that patients with IBD who associate a wide range of symptoms to their illness experience a greater disability. It has been postulated that patients misattribute unrelated symptoms to IBD, leading to a perception of greater disease activity and subsequently to disability. ${ }^{10}$ Our findings are in line with previous studies in IBD and other immunemediated inflammatory diseases demonstrating illness identity to be strongly associated with increased disability $\left(\mathrm{IBD}^{16} ; \mathrm{RA}^{11,28}\right.$ and psoriasis $^{12,28}$ ), reduced QOL $\left(\mathrm{IBD}^{29,30} ; \mathrm{RA}^{28}\right.$ and psoriasis $\left.{ }^{12}\right)$, and psychological distress $\left(\mathrm{RA}^{31}\right)$. Emotional response was also strongly and independently associated with disability in patients with CD and UC. The latter finding concurs with previous studies in patients with $\operatorname{IBD}^{15,29,30}$ and indicates that negative beliefs about the effects of illness on the patient's emotional status (in terms of anxiety and depression) result in the perception of a greater disability.

Personal control was strongly and independently associated with disability in patients with CD but not in UC. This suggests that patients with $\mathrm{CD}$ with less personal controllability of their illness experience a greater disability. The fact that personal controllability was not statistically significantly associated with disability in UC might be explained by the fact that patients with $\mathrm{CD}$ were more likely to have a stoma. Patients with a stoma can be expected to have specific problems and concerns, such as leakage, and inability to control gas, which may compromise their 
TABLE 2. Independent Determinants of Self-reported Disability in Patients with CD $(n=554)$ and UC $(n=424)$

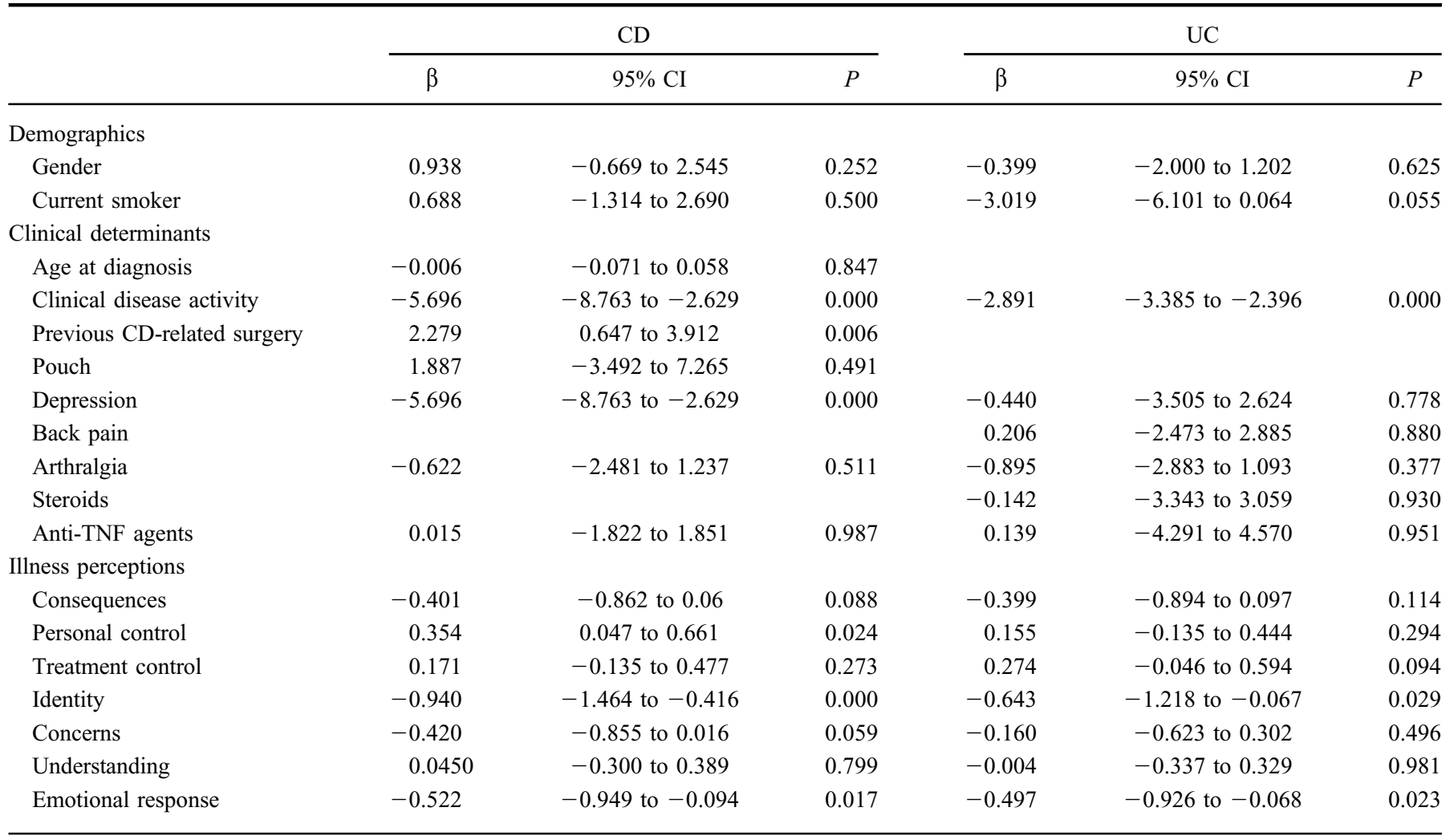

control over the illness. ${ }^{32}$ It may also be possible that the impact of personal control on disability in UC is canceled out by other factors, including the relapse rate. In our cohort, the relapse rate during 2 years of follow-up was significantly higher in patients with UC compared with CD (data not shown).

Finally, we have demonstrated that mean DHC increased and mean QOL scores decreased significantly with increasing of disability in patients with IBD. These findings strongly suggest that preventing disability in IBD may be a useful strategy to reduce future direct and indirect health care costs and burden to society.

This study has several strengths. First, the self-reported IBD disability index showed a good reliability and agreement with the interview-based disability index. Therefore, the self-reported IBD disability index can be used in web-based questionnaires, which may facilitate clinical research. Second, the large sample size enabled us to assess a large panel of potential determinants of disability. Third, patients were included from both university and general hospitals, thereby in our view, reliably representing the average patient with IBD in the Netherlands.

Several limitations of this study need to be addressed as well. First, an inherent limitation to the web-based design of this study is sampling bias. Although one might assume that disabled patients are more willing to fill out the questionnaires, we did not observe statistically significant differences between responders and nonresponders regarding relevant demographics, disease characteristics, and DHC. Second, self-reported data on comorbid conditions (e.g., depression) may be inaccurate. Third, potential determinants of functional disability, including endoscopic and laboratory markers of disease activity (CRP, fecal calprotectin), were not available. Fourth, as we performed a cross-sectional analysis, correlations between demographic, clinical, and behavioral variables and disability do not imply causality. For example, the inverse correlation that was found between anti-TNF treatment and disability may be caused by confounding by indication. Fifth, although we assessed the agreement between the patient-reported and interview-based IBD disability index, additional studies are required to determine the construct validity, discriminant ability, test-retest reliability, and responsiveness of the patient-reported IBD disability index.

Our findings underscore the importance of addressing and understanding patients' symptoms and perceptions of IBD. This relevant information allows clinicians to guide counseling and tailoring medical and biopsychosocial interventions to a patient's specific needs, potentially resulting in less disability, lower health care costs and a higher QOL. Previous studies have already shown that behavioral interventions based on the Common Sense Model of self-regulation can change illness perceptions of patients after myocardial infarction and patients with end-stage renal disease and thereby improve major components of QOL (i.e., return to work). ${ }^{33,34}$ 
In conclusion, our results clearly show that disability in IBD is associated with clinical disease activity and illness perceptions but not with a longer disease duration or an unfavorable disease phenotype. Greater disability is associated with higher costs and lower QOL. Because illness perceptions are potentially modifiable factors, they may provide a relevant target for interventions aimed at improving disability and other health outcomes. Future studies should focus on the additional value of the IBD disability compared with current symptom-assessment tools.

\section{ACKNOWLEDGMENTS}

The authors gratefully acknowledge the help of professor Rupert W. Leong, who provided the IBD disability index scoring system.

Author contributions: M. Van der Have had full access to all data in the study and takes responsibility for the integrity of the data and the accuracy of the data analysis. study concept and design: M. E. Van der Valk, B. Oldenburg, H. H. Fidder, M. van der Have; patient enrollment: A. A. Van Bodegraven, G. Dijkstra, H. H. Fidder, D. J. de Jong, M. Pierik, C. Y. Ponsioen, A. E. van der Meulen-de Jong, C. J. van der Woude, P. C. van de Meeberg, M. J. L. Romberg-Camps, C. H. M. Clemens, J. M. Jansen, N. Mahmmod, C. J. M. Bolwerk, J. R. Vermeijden; acquisition of data: M. van der Have, B. Oldenburg, H. H. Fidder, A. A. Kaptein; drafting of manuscript: M. van der Have; analysis and interpretation of data: M. van der Have, B. Oldenburg, H. H. Fidder; critical revision of the manuscript: All authors; statistical analysis: M. Leenders, M. van der Have; study supervision: B. Oldenburg.

\section{REFERENCES}

1. Cosnes J, Gower-Rousseau C, Seksik P, et al. Epidemiology and natural history of inflammatory bowel diseases. Gastroenterology. 2011;140: 1785-1794.

2. Peyrin-Biroulet L, Loftus EV Jr, Colombel JF, et al. The natural history of adult Crohn's disease in population-based cohorts. Am J Gastroenterol. 2010;105:289-297.

3. Graff LA, Walker JR, Clara I, et al. Stress coping, distress, and health perceptions in inflammatory bowel disease and community controls. Am J Gastroenterol. 2009;104:2959-2969.

4. Rogola L, Miller N, Graff L, et al. Population-based controlled study of social support, self-perceived stress, activity and work issue, and access to health care in inflammatory bowel disease. Inflamm Bowel Dis. 2008;14: 526-535.

5. Harvey RF, Bradshaw JM. A simple index of Crohn's disease activity. Lancet. 1980;1:514.

6. Guyatt GH, Mitchell A, Irvine EJ, et al. A new measure of health status for clinical trials in inflammatory bowel disease. Gastroenterology. 1989; 96:804-810.

7. Peyrin-Biroulet L, Cieza A, Sandborn WJ, et al. Disability and health international classification of functioning, inflammatory bowel disease based on the international classification of functioning, disability and health. Gut. 2012;61:241-247.

8. Peyrin-Biroulet L, Cieza A, Sandborn WJ, et al. Disability in inflammatory bowel diseases: developing ICF Core Sets for patients with inflammatory bowel diseases based on the International Classification of Functioning, Disability, and Health. Inflamm Bowel Dis. 2010;16:15-22.

9. World Health Organization. International Classification of Functioning, Disability and Health (ICF). Geneva, Switzerland: WHO; 2001. http:// www.who.int/classifications/icf/en. Accessed December 2013.
10. Leventhal H, Brissette I, Leventhal EA. The Common-Sense Model of self-regulation of health and illness. In: Cameron LD, Leventhal H, eds. The Self-regulation of Health and Illness Behaviour. London, United Kingdom: Routledge; 2003:42-65.

11. Bijsterbosch J, Scharloo M, Visser AW, et al. Illness perceptions in patients with osteoarthritis: change over time and association with disability. Arthritis Rheum. 2009;61:1054-1061.

12. Scharloo M, Kaptein AA, Weinman J, et al. Patients' illness perceptions and coping as predictors of functional status in psoriasis: a 1-year follow-up. Br J Dermatol. 2000;142:899-907.

13. Dalbeth N, Petrie KJ, House M, et al. Illness perceptions in patients with gout and the relationship with progression of musculoskeletal disability. Arthritis Care Res (Hoboken). 2011;63:1605-1612.

14. Coenen M, Cieza A, Stamm TA, et al. Validation of the International Classification of Functioning, Disability and Health (ICF) Core Set for rheumatoid arthritis from the patient perspective using focus groups. Arthritis Res Ther. 2006;8:R84.

15. Kiebles JL, Doerfler B, Keefer L. Preliminary evidence supporting a framework of psychological adjustment to inflammatory bowel disease. Inflamm Bowel Dis. 2010;16:1685-1695.

16. Dorrian A, Dempster M, Adair P. Adjustment to inflammatory bowel disease: the relative influence of illness perceptions and coping. Inflamm Bowel Dis. 2009;15:47-55.

17. Siebert U, Wurm J, Gothe RM, et al. Predictors of temporary and permanent work disability in patients with inflammatory bowel disease: results of the Swiss inflammatory bowel disease cohort study. Inflamm Bowel Dis. 2013;19:847-855.

18. Høivik ML, Moum B, Solberg IC, et al. Work disability in inflammatory bowel disease patients 10 years after disease onset: results from the IBSEN Study. Gut. 2013;62:368-375.

19. Leong R, Huang T, Ko Y, et al. Prospective validation study of the International Classification of Functioning, Disability and Health score in Crohn's disease and ulcerative colitis. J Crohns Colitis. 2014;8: 1237-1245.

20. Van der Valk ME, Mangen MJ, Leenders M; on behalf COIN study group and the Dutch Initiative on Crohn and Colitis. Healthcare costs of inflammatory bowel disease have shifted from hospitalisation and surgery towards anti-TNF $\alpha$ therapy: results from the COIN study. Gut. 2014;63: 72-79.

21. Broadbent E, Petrie KJ, Main J, et al. The brief illness perception questionnaire. J Psychosom Res. 2006;60:631-637.

22. Hakkaart-van Roijen L, Tan SS, Bouwmans CAM. Handleiding voor kostenonderzoek, methoden en standaard kostprijzen voor economische evaluaties in de gezondheidszorg. [Manual for Costing: methods and Reference Prices for Economic Evaluations in Healthcare] College voor zorgverzekeringen Geactualiseerde versie. Diemen 2010.

23. Russel MG, Pastoor CJ, Brandon S, et al. Validation of the Dutch translation of the inflammatory bowel disease questionnaire (IBDQ): a health-related quality of life questionnaire in inflammatory bowel disease. Digestion. 1997;58:282-288.

24. Bland JM, Altman DG. Statistical methods for assessing agreement between two methods of clinical measurement. Lancet. 1986;1:307-310.

25. Allen PB, Peyrin-Biroulet L. Moving towards disease modification in inflammatory bowel disease therapy. Curr Opin Gastroenterol. 2013;29: 397-404.

26. Israeli E, Graff LA, Clara I, et al. Low prevalence of disability among patients with inflammatory bowel disease a decade after diagnosis. Clin Gastroenterol Hepatol. 2014;12:1330-1337.

27. Hagger MS, Orbell S. A meta-analytic review of the common sense model of illness representations. Psychol Health. 2003;18:141-184.

28. Scharloo M, Kaptein AA, Weinman J, et al. Illness perceptions, coping and functioning in patients with rheumatoid arthritis, chronic obstructive pulmonary disease and psoriasis. J Psychosom Res. 1998;44: 573-585.

29. Han SW, McColl E, Barton JR, et al. Predictors of quality of life in ulcerative colitis: the importance of symptoms and illness representations. Inflamm Bowel Dis. 2005;11:24-34.

30. Van der Have M, Minderhoud IM, Kaptein AA, et al. Substantial impact of illness perceptions on quality of life in patients with Crohn's disease. J Crohns Colitis. 2013;7:e292-e301. 
31. Van Os S, Norton S, Hughes LD, et al. Illness perceptions account for variation in positive outlook as well as psychological distress in rheumatoid arthritis. Psychol Health Med. 2012;17: 427-439.

32. Carlsson E, Bosaeus I, Nordgren S. What concerns subjects with inflammatory bowel disease and an ileostomy? Scand J Gastroenterol. 2003;38: 978-984.
33. Petrie KJ, Cameron LD, Ellis CJ, et al. Changing illness perceptions after myocardial infarction: an early intervention randomized controlled trial. Psychosom Med. 2002;64:580-586.

34. Karamanidou C, Weinman J, Horne R. Improving haemodialysis patients' understanding of phosphate-binding medication: a pilot study of a psychoeducational intervention designed to change patients' perceptions of the problem and treatment. Br J Health Psychol. 2008;13:205-214. 